\title{
IDENTIFIKASI DAN ISOLASI SENYAWA LIKOPEN DARI SEMANGKA (CITRULLUS LANATUS)
}

\author{
Eva Monica ${ }^{1)}$, Rollando Rollando ${ }^{2 *}$ \\ ${ }^{1,2}$ Program Studi Farmasi, Fakultas Sains dan Teknologi, Universitas Ma Chung \\ Jl. Villa Puncak Tidar Blok N-01, Malang-Jawa Timur Indonesia-65151 Telp: (0341) 550171 \\ ro.llando@machung.ac.id
}

\begin{abstract}
INTISARI
Likopen adalah salah satu senyawa fitokimia dari golongan karotenoid penghasil utama pemberi pigmen berwarna merah yang terdapat pada semangka. Semangka merupakan tanaman merambat berbentuk bulat mengandung vitamin $\mathrm{C}$ dan vitamin A serta memiliki kadar antioksidan tinggi. Penelitian ini bertujuan untuk mengidentifikasi senyawa likopen dalam semangka. Ekstraksi daging buah semangka dengan metode maserasi. Identifikasi senyawa likopen dengan instrumen spektrofotometri UV-Visibel yang diikuti identifikasi dengan metode KLT dan fraksinasi ekstrak menggunakan KLT preparatif dengan pelarut kloroform:etanol (1:1), serta identifikasi hasil fraksinasi dengan Fourier Transform Infrared Spectroscopy (FT-IR). Hasil Penelitian identifikasi ekstrak buah semangka menggunakan metode KLT didapatkan tiga spot dan pada hasil spektrofotometri UV-Vis menunjukkan tiga puncak yaitu antara 440-520 nm. Pada identifikasi fraksinasi ekstrak buah semangka dengan menggunakan FT-IR didapatkan gugus penyusun dari struktur likopen, akan tetapi tidak menunjukkan gugus $\mathrm{R}-\mathrm{CH}=\mathrm{CH}-\mathrm{R}$ yang dimiliki likopen, sedangkan pada hasil uji dengan spektrofotometri UV-Vis panjang gelombang yang muncul berada pada 206 dan 245 yang menunjukkan keberadaan senyawa lain. Dari hasil penelitian dapat disimpulkan bahwa pada pengujian identifikasi ekstrak diketahui buah semangka memiliki kandungan senyawa likopen, akan tetapi pada pengujian identifikasi likopen pada hasil fraksinasi ekstrak buah semangka tidak ditemukan dengan pasti keberadaan likopen karena pada hasil FT-IR hanya ditunjukkan gugus-gugus yang terkandung dan pada hasil Spektrofotometri UV-Vis ditemukan panjang gelombang dari senyawa lain.
\end{abstract}

kata kunci: Semangka, Likopen, Spektrofotometri UV-Vis, Spektrofotometri IR

\begin{abstract}
Lycopene is one of the phytochemical compounds of the carotenoid group, the main producer of red pigments found in watermelons. Watermelon is a round-shaped vines containing vitamin $\mathrm{C}$ and vitamin $\mathrm{A}$ and has high antioxidant levels. This study aims to identify lycopene compounds in watermelons. Extraction of watermelon flesh by maceration method. Identification of lycopene compounds with UV-Visibel spectrophotometry instrument followed by identification with the TLC method and fractionation of extracts using preparative TLC with chloroform: ethanol (1: 1) solvents, and identification of fractionation results with Fourier Transform Infrared Spectroscopy (FT-IR). The results of the identification of watermelon fruit extract using the TLC method obtained three spots and the results of UV-Vis spectrophotometry showed three peaks namely between $440-520 \mathrm{~nm}$. The identification of fractionation of watermelon extract using FT-IR obtained a constituent group of lycopene structures, but did not show the $\mathrm{R}-\mathrm{CH}=\mathrm{CH}-\mathrm{R}$ group that is owned by lycopene, whereas the results of the test with UV-Vis spectrophotometry appearing at 206 and 245 which indicate the presence of other compounds. From the results of the study it can
\end{abstract}


be concluded that the testing of known extracts of watermelon fruit contains lycopene compounds, but the testing of lycopene identification on the results of fractionation of watermelon fruit extracts was not found with certainty the existence of lycopene because the FT-IR results were only shown and contained on the results UV-Vis spectrophotometry was found to be the wavelength of other compounds.

keywords: Watermelon, Lycopene, UV-Vis Spectrophotometry, IR Spectrophotometry

Corresponding author:

Rollando

Program Studi Farmasi, Fakultas Sains dan Teknologi, Universitas Ma Chung

Jl. Villa Puncak Tidar Blok N-01, Malang-Jawa Timur Indonesia-65151

Email: ro.llando@machung.ac.id

\section{PENDAHULUAN}

Likopen adalah salah satu senyawa fitokimia dari golongan karotenoid penghasil utama pemberi pigmen berwarna merah yang terdapat pada semangka dan buah-buahan lain yang berwarna merah. Likopen merupakan antioksidan yang sangat kuat, mempunyai BM 536,87, titik cair $172-173^{\circ} \mathrm{C}$, rumus molekul $\mathrm{C}_{40} \mathrm{H}_{56}$, serta karotenoid asiklis terbuka tak jenuh dengan 13 ikatan rangkap, 11 diantaranya ikatan rangkap terkonjugasi linier serta tidak mempunyai aktivitas provitamin A.

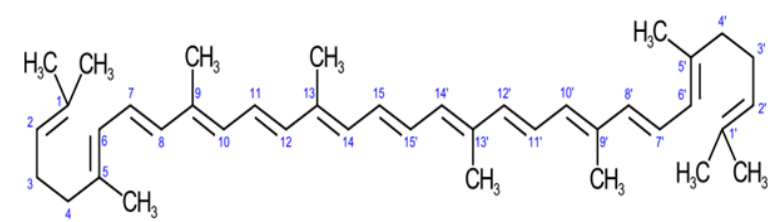

Gambar 1. Struktur Likopen

Struktur khas dari likopen menunjukkan sifat unik antioksidan dengan kemampuan mengikat oksigen tunggal dan menangkap peroksida.Mampu mengikat oksigen tunggal dua kali lebih tinggi daripada $\beta$-karoten dan sepuluh kali lebih kuat daripada $\alpha$-tokoferol. Likopen berbentuk kristal jarum, panjang, dengan bentuk tepung yang berwarna kecoklatan. Terlarut dalam benzene, heksen, kloroform dan pelarut organik yang bersifat hidrofobik kuat. Mampu mengalami degradasi dengan asam, proses isomerasi dan oksidasi akibat cahaya, oksigen, suhu tinggi, teknik pengeringan, penyimpanan dan proses pengelupasan.

Likopen merupakan suatu senyawa yang penting, bukan hanya karena penggunannya sebagai pewarna alami makanan tetapi juga karena likopen telah diakui memiliki manfaat bagi kesehatan (Nur Syafaatur dkk., 2015). Pada pembentukan likopen, suhu mempunyai peranan penting, jika suhu naik maka likopen akan semakin banyak terbentuk. (Sari dkk., 2007). Pemisahan likopen dari buah semangka dapat dilakukan dengan metode ekstraksi cair-cair, menggunakan $n$-heksan atau etanol sebagai solven, serta pengujian kadar likopen dengan menggunakan spektrofotometer.

Tanaman semangka merupakan tanaman merambat yang masih kerabat dari labu-labuan (Cucurbitaceae), melon (Cucumismelo) dan ketimun (Cucumissativus). Dalam buah semangka terdapat kandungan zat-zat yang sangat berguna bagi kesehatan tubuh manusia. Manfaat dari kandungan buah semangka antara lain melindungi jantung, memperlancar pengeluaran urine, dan menjaga kesehatan kulit. Semangka termasuk keluarga Cucurbitaceae, tidak hanya memiliki fungsi penghilang dahaga, tetapi berkhasiat antioksidan yang baik.Buah berbentuk bulat yang mengandung vitamin $\mathrm{C}$ dan vitamin A dengan jumlah besar. Dengan kadar antioksidan yang tinggi, semangka dapat diandalkan sebagai penetral radikal bebas dan mengurangi kerusakan sel dalam tubuh (Laila dkk., 2012).

\section{METODE PENELITIAN \\ Alat dan Bahan}


Alat yang digunakan terdiri dari corong pisah $250 \mathrm{ml}$, cawan penguap, neraca analitik, plat KLT, gelas ukur $10 \mathrm{ml}$, erlenmeyer $50 \mathrm{ml}$, blender, evaporator, pinset, oven, spektrofotomer UVVis dan FT-IR. Bahan yang digunakan terdiri dari buah semangka, kloroform, etanol, n-heksan, silica gel 60, dan aquades.

\section{Preparasi Buah Semangka}

Disiapkan 1 buah semangka merah yang masih segar yang didapatkan di pasar mergan Dieng Malang. Di ambil daging semangka, kemudian diblender hingga halus. Saring jus buah semangka.

\section{Ekstraksi Buah Semangka}

Ditimbang jus semangka 1000 gram, lalu dimasukkan ke dalam toples. Tambahkan $300 \mathrm{ml} n$ heksan ke dalam toples dan gojok kuat dan dibiarkan hingga larutan terpisah menjadi 2 fase yaitu fase air dan fase $n$-heksan yang mengandung likopen. Diambil bagian fase $n$-heksan, lalu di evaporasi menggunakan evaporator pada suhu $40^{\circ} \mathrm{C}$ dengan kecepatan $75 \mathrm{rpm}$. Hasil evaporasi diuapkan di atas waterbath pada suhu $40^{\circ} \mathrm{C}$ hingga didapatkan ekstrak kering. Hasil ekstraksi ditimbang kemudian dihitung :

$$
\text { \%Yield : } \frac{\text { Berat Ekstrak Akhir }}{\text { Bekstrak awal }} X 100 \%
$$

Identifikasi Likopen dari Ekstrak Buah Semangka dengan Spektrofotometri UV-Vis.

Ditimbang ekstrak semangka $10 \mathrm{mg}$, lalu dimasukkan ke dalam tube. Ditambahkan $3 \mathrm{ml}$ petroleum eter ke dalam tube. Kocok tube hingga ekstrak dapat homogen. Larutan dimasukkan ke dalam labu ukur $10 \mathrm{ml}$ dan ditambahkan petroleum eter hingga tanda kalibrasi. Ukur absorbansi larutan dengan spektrofotometri UV-Vis pada panjang gelombang 300-600 nm.

Identifikasi Likopen dalam Ekstrak Buah Semangka dengan Kromatografi Lapis Tipis.

Diukur plat KLT dengan panjang $10 \mathrm{~cm}$ dan lebar $1 \mathrm{~cm}$, lalu dipanaskan di oven pada suhu $110^{\circ} \mathrm{C}$ selama 15 menit. Dibuat pelarut untuk fase gerak menggunakan kloroform : etanol (1:1). Ekstrak dilarutkan dengan etanol. Dibuat spot larutan ekstrak pada plat KLT. Tunggu spot hingga mencapai batas, lalu dikeringkan. Amati spot pada sinar UV $366 \mathrm{~nm}$ dan hitung nilai RF.

\section{Pembuatan KLT-Preparatif}

Ditimbang silica gel 30 gram. Ditambahkan aquadest $70 \mathrm{ml}$ dan dicampur hingga homogen. Disiapkan cetakan KLT-Preparatif ukuran $20 \mathrm{~cm}$ X $20 \mathrm{~cm}$. Tuangkan larutan silica gel dengan ketebalan yang diinginkan pada cetakan. Diamkan silica gel hingga kering dan di oven pada suhu $100^{\circ} \mathrm{C}$.

\section{Fraksinasi likopen menggunakan KLT-Preparatif}

Ditimbang ekstrak $10 \mathrm{mg}$ dan dimasukkan tube, lalu ditambahkan etanol $20 \mathrm{ml}$ dan di gojok hingga homogen. Dibuat larutan fase gerak sebanyak $20 \mathrm{ml}$ dengan campuran kloroform : etanol (1:1) dan dimasukkan ke dalam camber. Dibuat garis lintas spot $17 \mathrm{~cm}$ pada plat KLT-Preparatif. Buat spot larutan ekstrak dengan pipa kapiler. Letakkan plat KLT-Preparatif pada camber dan ditunggu hingga spot sampaipada tanda batas. Dibiarkan pat KLT-Prepaatif hingga kering, kemudian amati pada sinar UV dengan panjang gelombang $366 \mathrm{~nm}$. Spot yang terbentuk diambil dan disimpan pada wadah botol vial. Serbuk yang dihasilkan dilarutkan dengan campuran larutan kloroform : etanol (1:1) hingga serbuk berwarna putih. Larutan yang dihasilkan diuapkan pada suhu ruang hingga didapatkan ekstrak etanol yang kering.

Identifikasi Likopen dari fraksinasi ekstrak buah semangka dengan FT-IR.

Ekstrak likopen yang dihasilkan dari hasil fraksinasi diukur absorbansinya menggunakan FTIR. Dilakukan pembersihan pada alat dengan pelarut yang sesuai dengan sifat ekstrak buah semangka. UV-Vis.

Identifikasi likopen dari fraksinasi ekstrak buah semangka dengan Spektrofotometri

Ekstrak likopen yang dihasilkan dari proses fraksinasi dilarutkan dengan etanol sebanyak 3 ml. Kemudian diukur absorbansi larutan pada panjang gelombang 200-600 nm dengan spektrofotometri UV-Vis. Dilakukan pembersihan pada alat dengan pelarut yang sesuai dengan sifat ekstrak buah semangka.

\section{HASIL DAN PEMBAHASAN}




\section{Ekstraksi}

Ekstraksi buah semangka menggunakan metode cair-cair dengan pelarut n-hexsan didapatkan hasil sebesar 0,515 gram atau sebesar 0,0515\%. Hasil yang didapatkan sangat sedikit, hal ini dikarenakan kadar air dalam semangka sangat tinggi sehingga senyawa yang dapat larut ke dalam pelarut hanya sebagian kecil (Mariani dkk, 2018).

Identifikasi Ekstrak Semangka dengan Spektrofotometri UV-Vis.

Ekstrak yang didapatkan dari proses ekstraksi kemudian di identifikasi senyawa lycopene menggunakan spektrofotometri UV-Vis pada panjang gelombang 300-600 nm. Pada pengujian identifikasi ekstrak semangka terdapat 3 puncak pada panjang gelombang $440-520 \mathrm{~nm}$ seperti pada gambar 2.Hasil yang didapatkan memungkinkan bahwa ekstrak buah semangka mengandung senyawa likopen hal ini dikarena senyawa likopenakan muncul pada panjang gelombang $472 \mathrm{~nm}$ (Tupe dkk , 2015).

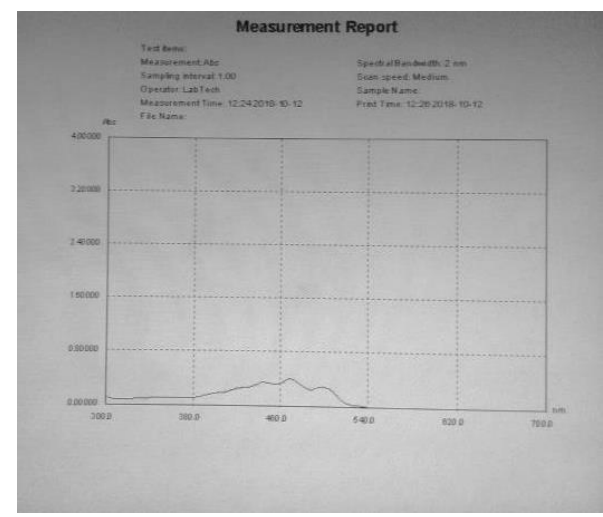

Gambar 2. Hasil Identifikasi Ekstrak Semangka dengan Spektrofotometri UV-vis

\section{Identifikasi Ekstrak Semangka dengan metode KLT}

Identifikasi senyawa likopendilakukan juga menggunakan metode KLT. Metode ini dilakukan untuk melihat nilai Rf pada ekstrak serta digunakan untuk mencari konsentrasi pelarut yang tepat untuk uji menggunakan KLT preparatif. Senyawa likopen akan terdeteksi pada rentan 0,1 ingga 0,8 dengan warna merah atau orange. ( Roh dkk, 2013). Pemilihan Fase gerak sangat penting dan harus disesuaikan dengan tingkat kepolaran terhadap senyawa yang ingin kita uji.Seperti pada likopenmerupakan senyawa non polar sehingga di perlukan fase gerak non polar atau semipolar (Saeid dkk, 2016).

Nilai Rf yang didapat dari metode KLT sanggat tinggi dan tidak terdapat pemisahan serta berwarna Orange pada percobaan pertama. Sehingga dilakukan pencarian pelarut yang tepat untuk memisahkan senyawa.Dari beberapa kali percobaan didapatkan pelarut yang cocok yaitu pelarut kloroform dan etanol (1:1).Penggunaan Kloroform dan etanol menghasilkan 3 spot tetapi masih terjadi tailing. Adanya beberapa spot menunjukan jika ekstrak semangka yang dimiliki mengandung lebih dari satu senyawa. Sehingga perlu dilakukan fraksinasi untuk memisahkan spotspot yang nantinya akan di identifikasi untuk menemukan senyawa likopen dengan metode KLT-P.

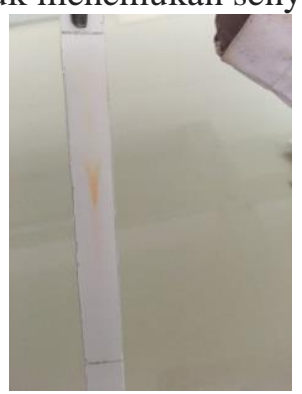

Gambar 3. KLT (klorofrom dan etanol)

Fraksinasi likopen dengan metode KLT Preparatif

Pada proses fraksinasi digunakan klorofrom dan etanol sebagai fase gerak untuk memisakan senyawa. Dari proses KLT-P didapatkan 3 spot yang berbeda yang dilihat dari sinar UV $366 \mathrm{~nm}$ 
dan $265 \mathrm{~nm}$ seperti pada gambar 4. Kemudian 3 spot berbeda sebelum di identifikasi di lakukan pencucian terlebih dahulu menggunakan pelarut yang sama dengan fase geraknya. Hasil yang didapatkan karena terlalu sedikit kemudian akan dilakukan analisis menggunakan IR dan UV-Vis.

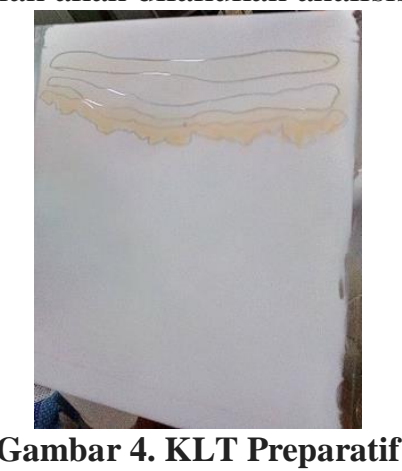

\section{Karakteristik Fraksinasi ekstrak buah semangka dengan FT-IR.}

Karakteristik fraksinasi ekstrak buah semangka dengan FT-IR dilakukan untuk mengidentifikasi gugus fungsi dari senyawa likopen.Likopen memiliki struktur $\mathrm{C}_{40} \mathrm{H}_{56}$ sehingga di perlukan pengujian menggunakan FT-IR untuk mengetahui apakah semua gugus dari struktur likopen terpenuhi. Hasil pengujian isolat menggunakan FTIR dapat dilihat seperti pada gambar 5. FTR.jws

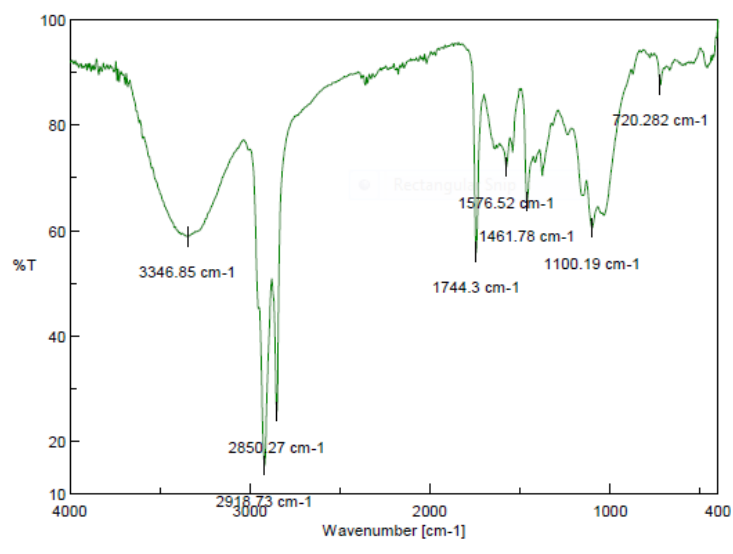

Gambar 5 Karakteristik FT-IR

Data spektrum likopen yang akan muncul pada puncak serapan seperti berikut : $720,282 \mathrm{~cm}^{-1}$ ; 1100,19 $\mathrm{cm}^{-1} ; 1461,78 \mathrm{~cm}^{-1} ; 1576,52 \mathrm{~cm}^{-1} ; 1744,3 \mathrm{~cm}^{-1} ; 2850,27 \mathrm{~cm}^{-1} ; 2918,73 \mathrm{~cm}^{-1}$ dan 3346,85 $\mathrm{cm}^{-1}$. Kemudian spktrum yang telah didapat dianalisis dengan bantuan beberapa acuan pada buku dan jurnal sehingga padat disimpulkan bahwa pada serapan 720,282 $\mathrm{cm}^{-1}$ menunjukan adanya gugus CH. Pada serapan 1100,19 $\mathrm{cm}^{-1}$ menunjukan gugus C-O streaching. Pada serapan 1461,78 $\mathrm{cm}^{-1}$ menunjukan gugus $\mathrm{CH}_{2}$ dari likopen, $1576,52 \mathrm{~cm}^{-1}$ dan $1744,3 \mathrm{~cm}^{-1}$ menunjukan adanya gugus cincin aromatis $\mathrm{C}=\mathrm{C}$ pada rantai likopen. Pada serapan $2850,27 \mathrm{~cm}^{-1}$ dan $2918,73 \mathrm{~cm}^{-1}$ menunjukan adanya gugus $\mathrm{C}-\mathrm{H}$ pada likopen serta pada serapan $3346,85 \mathrm{~cm}^{-1}$ memungkinkan tertapat gugus $\mathrm{O}-\mathrm{H}$ yang terbentuk dari uap air yang berikatan dengan likopen atau adanya ikatan absorbsi yang kuat dengan air (Christian dkk, 2015). Dari hasil FTIR yang didapatkan diketahui bahwa senyawa yang dianalisis memiliki gugus-gugus lycopene seperti yang diharapkan. Tetapi pada senyawa tidak memiliki gugus $\mathrm{R}-\mathrm{CH}=\mathrm{CH}-\mathrm{R}$ dari likopen yang terjadi pada serapan $960 \mathrm{~cm}^{-1}$ (Priam dkk, 2016).

\section{Identifikasi hasil Fraksinasi dengan Spektrofotomatri UV-Vis}

Pada pengujian menggunakan spektro UV- vis didapatkan puncak pada $206 \mathrm{~nm}$ dan $245 \mathrm{~nm}$ (Gambar 6). Pada panjang gelombang 206 dan 245 menunjukan adanya ikatan $\mathrm{C}=\mathrm{C}$ yang tidak terkonjugasi (Susilawati , 2016). Panjang gelombang 206 dan 245 dapat terjadi karena adanya transisi electron dari $\pi->\pi *$ ikatan rangkap diduga merupakan senyawa steroid (Maharani dkk, 
2016). Tetapi hal ini perlu di analisis lebih lanjut untuk membuktikan apakah memang terdapat senyawa steroid atau flavonoid atau hanya ketidak stabilan antara isolat dan pelarut.Peneliti lebih menyimpulkan bahwa panjang gelombang yang muncul pada serapan 206 dan 245 merupakan senyawa flavonoid hal ini dikarenakan semangka mengandung flavonoid tapi tidak mengandung steroid.

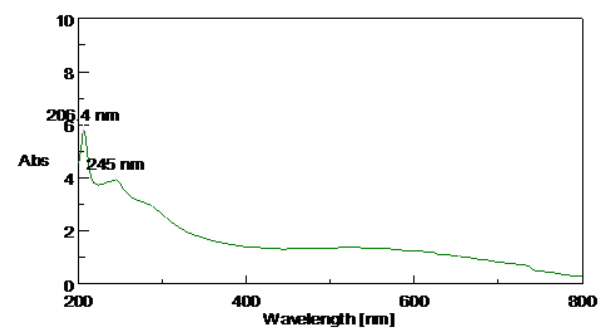

Gambar 6. Identifikasi Lycopene dengan UV-Vis

\section{KESIMPULAN}

Dari hasil penelitian dapat disimpulkan bahwa pada pengujian identifikasi ekstrak diketahui buaha semangka memiliki kandungan senyawa likopen, akan tetapi pada pengujian identifikasi likopen pada hasil fraksinasi ekstrak buah semangka tidak ditemukan dengan pasti keberadaan likopen karena pada hasil FT-IR hanya ditunjukkan gugus-gugus yang terkandung dan pada hasil Spektrofotometri UV-Vis ditemukan panjang gelombang dari senyawa lain.

harus jelas dan mencerminkan hasilnya

\section{DAFTAR PUSTAKA}

Christiant,D., Gavra,S.F., dan Masyithah, Z., 2015, Kristalisasi likopen dari buah Tomat (Lycopersicon esculentum) menggunakan antisolven, Jurnal Teknik Kimia USU, 4(4).

Laila D.R, Hesty K, Galih D.S. Niken I. M., 2012. Analisis Kadar Antioksidan pada Masker Wajah Berbahan Dasar Lapisan Putih Kulit Semangka (Citrullus Vulgaris Schrad). Seminar Nasional Penelitian, Pendidikan dan Penerapan MIPA, Fakultas MIPA, Universitas Negeri Yogyakarta.

Maharani, T., Sukandar, D dan Hermanto, S., 2016. Karakterisasi Senyawa Hasil Isolasi dari Ekstrak Etil Asetat Daun. Jurnal Kimia Valensi.2(1). 55-62

Mariani, S., Rahman, N., dan Supriadi. 2018. Uji Aktivitas Antioksidan Ekstrak Buah Semangka (Citrullus lanatus). Jurnal Akademika Kimia. 7(2):96-101.

Nur,S.R., Panji, R, Reka,,W, Rika M, dan Cikra NHS, 2015, Perbandingan Kadar Likopen pada Manilkara zapota L., Gnetum gnemon L., Ipomoea batatas L., dan Momordica charantia L. dengan Menggunakan Campuran Solven n-Heksan, Aseton, dan Etanol, Jurnal Farmasi Sains dan Terapan, 2(1).

Priam, F., Odile,M., Marcus,R., Jô, L.V, Ravin.E.J.S., 2016, Lycopene extraction from Psidium guajava L. and evaluation of its antioxidant properties using a modified DPPH test, IOSR Journal of Environmental Science, Toxicology and Food Technology. 67-73

Roh, M, K., and Hee. M.J, 2013, A Simple Method For The Isolation Of Lycopene From Lycopersicon Esculentum, Botanical Sciences. 91(2): 187-192.

Saeid,A., Eun J.B., Sagor M.S.A., Rahman A., Akter M.S., Ahmed M. 2016. Effects of Extraction and Purification Methods on Degradation Kinetics and Stability of Lycopene from Watermelon under Storage Conditions. Journal of Food Science 81(11):C2630-C2638.

Sari I.K, Kun T.D, Sunarmani.2007. Potensi Likopen dalam Tomat Untuk Kesehatan, Buletin Teknologi Pascapanen Pertanian, Vol. 3.11.

Susilawati, N., 2016. Isolasi dan identifikasi senyawa steroid dari daun Rimbang (Solanum Torvum).Skripsi. Riau. Universitas Negeri Riau.

Tupe, R.B., Patil, S.M., dan Sakhale, B.K., 2015, Extraction of lycopene by supercritical fluid extraction, International Journal of Science, Spirituality, Business and Technology, 3(2): 4348. 